\title{
Effects of prolonged continuous computer gaming on physical and ocular symptoms and binocular vision functions in young healthy individuals
}

\author{
Ji-Woo Lee ${ }^{1}$, Hyun Gug Cho ${ }^{2}$, Byeong-Yeon Moon ${ }^{2}$, Sang-Yeob Kim ${ }^{2}$, Dong-Sik Yu ${ }^{\text {Corresp. } 2}$ \\ 1 Department of Optometry and Vision Science, Kyungwoon University, Gumi, South Korea \\ 2 Department of Optometry, Kangwon National University, Samcheok, South Korea \\ Corresponding Author: Dong-Sik Yu \\ Email address: yds@kangwon.ac.kr
}

Background and Objective. Addiction to computer gaming has become a social problem in Korea and elsewhere, and it has been enlisted as a mental health disorder by the World Health Organization. Most studies related to computer use and vision have individually assessed physical and ocular symptoms and binocular vision. Accordingly, the present study comprehensively assessed subjective physical and ocular symptoms and functions related to binocular vision after prolonged continuous computer gaming. This study aimed to investigate the effects of prolonged continuous computer gaming on physical and ocular health and visual functions in young healthy individuals.

Methods. Fifty healthy college students (35 male/ 15 female), aged 19-35 years old, were enrolled in this study. The inclusion criteria were no binocular vision problems and no reported history of ocular disease. Participants played continuously for $4 \mathrm{~h}$ from 6:00 to 10:00 p.m. Physical and ocular symptoms and visual functions such as convergence, accommodation, phoria, and the blink rate were assessed before and after continuous computer gaming for $4 \mathrm{~h}$.

Results. Continuous computer gaming for $4 \mathrm{~h}$ resulted in convergence and accommodation disturbances and increased physical and ocular discomfort. Near phoria showed an exophoric shift, whereas distance phoria showed no change. Moreover, the accommodative and vergence facilities and blink rate were significantly decreased. All visual functions recovered to the baseline levels by the following morning.

Discussion. Our findings suggest that excessive and continuous computer gaming impairs visual functions and causes ocular and physical fatigue. Our findings further the understanding of the adverse effects of excessive computer use on physical and ocular health, and adequate breaks are necessary to reduce physical and visual discomfort during computer gaming. 
2 Effects of prolonged continuous computer gaming on 3 physical and ocular symptoms and binocular vision 4 functions in young healthy individuals

Ji-Woo Lee ${ }^{1}$, Hyun Gug Cho ${ }^{2}$, Byeong-Yeon Moon ${ }^{2}$, Sang-Yeob Kim² and Dong-Sik Yu ${ }^{2}$

${ }^{1}$ Department of Optometry and Vision Science, Kyungwoon University, Gumi, South Korea

${ }^{2}$ Department of Optometry, Kangwon National University, Samcheok, South Korea

Corresponding Author:

13 Dong-Sik Yu

Hwangjogil 346, Dogye-up, Samcheok, Gangwondo 25949, Republic of Korea

Email address: yds@kangwon.ac.kr

\section{ABSTRACT}

Background and Objective. Addiction to computer gaming has become a social problem in Korea and elsewhere, and it has been enlisted as a mental health disorder by the World Health Organization. Most studies related to computer use and vision have individually assessed physical and ocular symptoms and binocular vision. Accordingly, the present study comprehensively assessed subjective physical and ocular symptoms and functions related to binocular vision after prolonged continuous computer gaming. This study aimed to investigate the effects of prolonged continuous computer gaming on physical and ocular health and visual functions in young healthy individuals.

Methods. Fifty healthy college students (35 male/ 15 female), aged 19-35 years old, were enrolled in this study. The inclusion criteria were no binocular vision problems and no reported history of ocular disease. Participants played continuously for $4 \mathrm{~h}$ from 6:00 to 10:00 p.m. Physical and ocular symptoms and visual functions such as convergence, accommodation, phoria, and the blink rate were assessed before and after continuous computer gaming for $4 \mathrm{~h}$.

Results. Continuous computer gaming for $4 \mathrm{~h}$ resulted in convergence and accommodation disturbances and increased physical and ocular discomfort. Near phoria showed an exophoric shift, whereas distance phoria showed no change. Moreover, the accommodative and vergence facilities and blink rate were significantly decreased. All visual functions recovered to the baseline levels by the following morning. Discussion. Our findings suggest that excessive and continuous computer gaming impairs visual functions and causes ocular and physical fatigue. Our findings further the understanding of the adverse effects of excessive computer use on physical and ocular health, and adequate breaks are necessary to reduce physical and visual discomfort during computer gaming. 
40

41

42

43

44

45

46

47

48

49

50

51

52

53

54

55

56

57

58

59

60

61

62

63

64

65

66

67

68

69

70

71

72

73

74

75

76

77

78

79

\section{INTRODUCTION}

The ability to visualize near objects clearly and accurately is necessary for individuals using computers and other digital screen devices on a daily basis. In today's digital age, prolonged use of visual (or video) display terminals (VDTs) such as computers and smartphones has become very common and is one the main causes of ocular and physical discomfort (González-Pérez et al., 2014; Parihar et al., 2016). The majority of ocular and physical symptoms are associated with the effects of prolonged VDT usage on visual functions (Fenga et al., 2007; Tyrrell \& Leibowitz, 1990; Yeow \& Taylor, 1990, 1991). Computer vision syndrome (CVS), a condition associated with excessive computer use, is characterized by not only visual symptoms such as eyestrain, dry eyes, and blurred and double vision but also physical discomfort such as musculoskeletal shoulder disorders, neck pain, headache, and dizziness (Berqqvist et al., 1995; Hayes et al., 2007; Rosenfield, 2011). According to the Korea Games Users Survey Reports 2017, the rate of computer gaming in the general Korean population aged 10 to 65 years-old was increased from 67.9\% in 2016 to 70.3\% in 2017 (The Korea Creative Content Agency, 2017), which could lead to increased problems related to computer use.

Computer games have become a part of leisure activities in daily life, with young individuals spending excessive time indulging in such games (Wittek et al., 2016). The current most popular games require users to pay close attention to their VDTs, and the players show deep levels of emotional and physical addiction while gaming (Kim et al., 2016; Rikkers et al., 2016). Ubiquitous gaming cafes known as "PC bang" are very popular in Korea (Zastrow, 2017), where $24 \%$ of children are reportedly diagnosed with internet gaming addiction requiring hospitalization (Ahn, 2017). Computer gaming addiction can cause health and mental issues (Griffiths, Kussa \& King, 2012; Saquib et al., 2017). Furthermore, excessive computer use has been reported to cause problems associated with poor computer (Toomingas, 2014). A recent study showed that the neck and shoulder are the most commonly reported areas affected by excessive computer use (James et al., 2018). Other commonly reported symptoms include headache, eyestrain, double vision, dry eyes, and ocular fatigue (Akinbinu \& Mashalla, 2014). Some studies (Qu et al., 2005; Yekta, Pickwell, \& Jenkins, 1989) have also reported that near work on VDTs may cause not only ocular and physical symptoms but also transient changes in refraction, visual acuity, accommodation, and convergence. Tosha et al. (2009) examined the relationship between visual discomfort and the accommodation response in a college population with visual discomfort and found that increased visual discomfort is characterized by accommodative fatigue, with a higher lag of accommodation developing at a near viewing distance over time.

Furthermore, a study of over 1,173 Korean school-going children reported that the participants spent approximately $1.35 \mathrm{~h}$ on computer-based academics and $2.03 \mathrm{~h}$ on computer gaming during a normal day, and computer-using time was $3.6 \pm 2.2 \mathrm{~h}$ for internet-addicted Korean adolescents as reported by Yang et al. (2014). Computer overuse has led to progressive negative effects yearly in the users' physical and mental health, and the "shutdown law" was 
80

81

82

83

84

85

86

87

88

89

90

91

92

93

94

95

96

97

98

99

100

101

102

103

104

105

106

107

108

109

110

111

112

113

114

115

116

117

118

119

recently introduced in Korea for the protection of youth from internet-based computer games (Kim et al., 2016; Sung, 2014). The World Health Organization (WHO, 1987) has recommended that frequent minibreaks (of few seconds duration) must be taken while working with VDTs to prevent problems, while longer breaks are often advisable after one or two hours - depending on the job. However, it is difficult to ensure breaks in individuals who are engrossed in computer games. Actually, most individuals addicted or immersed to computer games tend to play for prolonged hours without a break, and the effects of prolonged continuous viewing of VDTs at a near distance on physical and ocular health remain unclear. Moreover, most studies related to computer use and vision has individually evaluated physical and ocular symptoms and binocular vision (Parihar et al., 2016; Hamed et al., 2013). Unlike many studies reported in the literature related to VDT, the current study examined physical and ocular symptoms and signs (binocular functions) resulting due to prolonged computer gaming without rest for $4 \mathrm{~h}$ (hours) at a time, which has not been evaluated till date. Therefore, we believe that a study focused on a comprehensive assessment of subjective physical and ocular symptoms and functions related to binocular vision after prolonged continuous computer use is necessary. Accordingly, the aim of this study was to investigate subjective physical and ocular symptoms and visual functions, as well as their interrelationships, after prolonged continuous computer gaming in young healthy individuals.

\section{METHODS}

\section{Participants}

This research complied with the tenets of the Declaration of Helsinki and was approved by the Institutional Review Board of Kangwon National University (KWNUIRB-2017-07-002-003). Informed consent was obtained from each participant.

Minimal required sample size was performed using GPower 3.1.2 software (Heinrich-HeineUniversität, Düsseldorf, Germany). With an alpha error of $0.05,90 \%$ power, effect size of 0.25 , 1 group, and 3 measurements, a sample size of 43 was calculated but fifty Korean healthy college students (age, 19-35 years, average age, 22.5 (mean) \pm 3.4 (SD, standard deviation) years; male:female, 35:15) who had maintained a daily routine without physical and ocular fatigue in their daily life were randomly enrolled as subjects for our study. The inclusion criteria were as follows: no near or distance vision problems; a corrected or uncorrected distance visual acuity of 20/25 (0.8) or better in each eye; normal stereopsis; and no reported history of ocular disease.

Twenty-nine subjects (58\%) wore spectacles, and their mean spherical equivalent power was $-1.99 \pm 2.53$ diopters (D).

This study was performed under immersive computer gaming that involved general tasks for a prolonged period $(4 \mathrm{~h})$ without a break versus a short period $(\leq 2 \mathrm{~h})$ of VDT exposure in order to determine the presence of physical and ocular discomfort.

\section{Procedures}

The subjects were asked to play a computer game (Diablo III, Blizzard Entertainment, USA) on 
120 a desktop computer screen (CX501N-KN/KOR with a 15-inch LCD monitor, Samsung, Korea) 121 from a viewing distance of $50 \mathrm{~cm}$ under room illumination (approximately $50 \mathrm{lux}$ ). They played 122 continuously for $4 \mathrm{~h}$ from 6:00 to 10:00 p.m. All subjects received a modified questionnaire 123 (Ames et al., 2005) designed for assessing the effects of virtual reality viewing on monocular, 124 binocular, and physical symptoms, as well as ophthalmological examinations for the assessment 125 of visual functions, before and after the gaming session.

126 The questionnaire included 13 items pertaining to four physical and nine ocular symptoms.

127 Each item was graded on a scale of 0 to $4(0=$ none, $1=$ slight, $2=$ moderate, $3=$ severe, and $4=$ 128 very severe).

129 Visual functions were measured under habitual viewing conditions. Visual acuity was measured 130 using visual charts (ACP-8, Topcon, Japan) and a phoropter (CV-3000, Topcon, Japan). The near 131 point of convergence (NPC) is to evaluate the convergence amplitude, which represents a visual 132 function to obtain single vision, was measured by bringing an accommodative target to the nose 133 and recording the point time at which the subject could see double (Scheiman et al., 2003). The

134

135

136

137

138

139

140

141

142

143

144

145

146

147

148

149

150

151

152

153

154

155

156

157

158

near point of accommodation (NPA) is the near point to measure the amplitude of accommodation under binocular conditions, which represents a visual function for maintaining a clear image (Abraham et al., 2005), was measured using an accommodative convergence rule (GR50, Bernell, USA) while the subject attempted to read small letters (near visual acuity, 20/32). Phoria is to assess the presence, direction, and amplitude of the eye alignment, which indicates latent misalignment of the eyes, was measured using Howell phoria cards (Wong, Fricke \& Dinardo, 2002) (CDHP, Bernell, USA) at $3 \mathrm{~m}$ and $33 \mathrm{~cm}$. Negative values indicate exophoria, whereas positive values indicate esophoria. Accommodative and vergence facilities is to evaluate the ability of the accommodative response and ability of the fusional veregence respectively(Weissberg, 2004; Gall, Wick \& Bedell, 1998), which were measured using a $\pm 2.0 \mathrm{D}$ binocular flipper lens and a prism flipper ( $3 \Delta$ base-in $+12 \Delta$ base-out; $\Delta$ : prism diopter) at 40 $\mathrm{cm}$. Blink rate was measured using a camcorder combining a video camera (NV-GS400, Panasonic, Japan), complete and incomplete blinks were distinguished by the presence of the full and partial eye cycle of open-close-open. Binocular function was measured at time-points of before and after the computer game, and the next morning.

\section{Statistical Analysis}

All data were statistically analyzed using SPSS (ver. 18.0 for Windows, SPSS Inc., Chicago, IL, USA). Pearson's correlation analysis, paired t-tests, and repeated measures analysis of variance (ANOVA) were used for statistical analyses. The level of significance was set at $p=0.05$. If significant differences were found, post hoc tests with Bonferroni corrections were used to identify the level of significance. Partial missing values in phoria and blink rate were excluded from descriptive statistics analyses.

\section{RESULTS}

Peer) reviewing PDF | (2018:10:31788:2:0:NEW 19 Mar 2019) 
159 The mean scores for the four physical (monocular) and nine ocular symptoms associated with

160

161

162

163

164

165

166

167

168

169

170

171

172

173

174

175

176

177

178

179

180

181

182

183

184

185

186

187

188

189

190

191

192

193

194

195

196

197

198

computer game use are shown in Table 1. The mean overall scores for the physical and ocular discomfort domains increased from $0.39 \pm 0.78$ and $0.50 \pm 0.83$, respectively, before the gaming session to $1.61 \pm 1.24(\mathrm{t}=15.7, \mathrm{p}<0.001)$ and $1.40 \pm 1.22(\mathrm{t}=17.44, \mathrm{p}<0.001)$, respectively, after the gaming session. The scores for all individual items also showed significant changes after the gaming session, and the mean difference was $1.00 \pm 0.33$. In the physical discomfort domain, the score for neck discomfort after the gaming session was the highest, followed by the scores for shoulder discomfort, headache, and back discomfort. In the ocular discomfort domain, the score for tired eyes was the highest $(2.30 \pm 1.09)$, followed by the scores for dry eyes, blurred vision, and eyestrain. The score for itchy eyes was the lowest $(0.82 \pm 1.00)$.

The effects of prolonged continuous computer gaming on visual functions are shown in Table 2. The mean NPC values showed significant changes immediately after and the morning after the gaming session $(\mathrm{F}=47.83, \mathrm{p}<0.001)$. A post hoc Bonferroni multiple comparisons test indicated that NPC significantly increased immediately after the gaming session (post hoc $\mathrm{p}<$ 0.001 for before and after) and recovered to the baseline level by morning (post hoc $\mathrm{p}=1.000$ for morning and before). The mean NPA value also showed significant changes $(\mathrm{F}=42.50, \mathrm{p}<$ 0.001). A multiple comparisons test with Bonferroni correction showed that the NPA value after the gaming session was significantly different from the next-day value and the baseline value (host hoc $\mathrm{p}<0.001$ for before and after, $\mathrm{p}<0.001$ for after and morning); the next-day value and the baseline value showed no significant differences (post hoc $p=1.000$ for morning and before).

The accommodative facility (AF) and vergence facility (VF) significantly decreased after the gaming session (post hoc $\mathrm{p}<0.001$ for before and after in both facilities)). Both facilities recovered to more than baseline levels by the following morning (post hoc $\mathrm{p}=0.001$ and $\mathrm{p}=$ 0.045 for morning and before in $\mathrm{AF}$ and $\mathrm{VF}$, respectively).

The blink rate before the gaming session was 16.24 times per minute; this significantly decreased to 8.27 and 9.51 times per minute at 1 and $4 \mathrm{~h}$ after the start of the game, respectively ( $F=106.29, p<0.001$; post hoc $p<0.001$ for before and after, $p=0.080$ for after $1 \mathrm{~h}$ and $4 \mathrm{~h}$ ).

The changes in phoria during the computer gaming session are shown in Fig. 1. Near phoria showed an exophoric shift (exophoria) during the session (repeated measures ANOVA; $\mathrm{F}=$ $24.25, \mathrm{p}<0.001$, post hoc $\mathrm{p}=1.000$ for after $1 \mathrm{~h}$ and $2 \mathrm{~h}, \mathrm{p}=0.010$ for after $2 \mathrm{~h}$ and $3 \mathrm{~h}, \mathrm{p}<$ 0.001 for after $3 \mathrm{~h}$ and $4 \mathrm{~h}$ ) ) and recovered to baseline levels by the following morning (post hoc $\mathrm{p}=1.000$ for morning and before). Distance phoria showed no significant differences during the game (repeated measures ANOVA; $\mathrm{F}=0.61, \mathrm{p}=0.610$ ). Horizontal phoria at distance showed no statistically significant differences among before, after, and the day after the gaming session $(\mathrm{F}=1.67, \mathrm{p}=0.193)$, whereas horizontal phoria at near changed from $-3.73 \pm 3.93$ before the gaming session to $-5.75 \pm 4.85$ and $-3.68 \pm 4.86$ immediately after and the day after the gaming session, respectively $(F=18.39, p<0.001$; post hoc $p<0.001$ for befor and after, $p<0.001$ for after and morning, $p=1.000$ for morning and before).

Pearson's correlation analysis showed a very weak negative correlation between itchy eyes and NPC after the gaming session $(r=-0.294, p=0.039)$ and a weak positive correlation

Peer) reviewing PDF | (2018:10:31788:2:0:NEW 19 Mar 2019) 
199

200

201

202

203

204

205

206

207

208

209

210

211

212

213

214

215

216

217

218

219

220

221

222

223

224

225

226

227

228

229

230

231

232

233

234

235

236

237

238

between tired eyes and NPA $(r=0.361, p=0.01)$ and between blurred vision and NPA $(r=$ $0.298, \mathrm{p}=0.036)$ after the gaming session.

\section{DISCUSSION}

Our results are not limited to gaming activities, but applicable under the environment of overuse of personal computers for the purpose of computer game after the college students' work day. There were several differences between the current study and the previous studies (Yeow \& Taylor, 1990, 1991; Qu et al., 2005). Our study describes game-based VDT activity in contrast to work-based VDT, continuous 4-h exposure in contrast to short-term 1-2.35-h or long-term exposure, physical and ocular symptoms in contrast to ocular symptoms alone, assessment of accommodative facility and vergence facility besides NPC, NPA, phoria as binocular functions, and measured sessions of a recovery point besides before and after. In the present study, we found that prolonged continuous computer use for gaming resulted in both physical and ocular discomfort as well as changes in binocular functions. In particular, the neck and shoulder, which remain in the same posture while playing, were affected. The major visual symptom was ocular fatigue (tired eyes), followed by dryness and blurred vision. These findings are consistent with those of other studies (Hayes et al., 2007; Klussmann et al., 2008) reporting a high prevalence of neck and shoulder symptoms, ocular fatigue, and blurred vision after excessive computer use. The findings of a 13-item questionnaire used in our study revealed higher scores for physical symptoms than for ocular symptoms after 4 continuous hours of gaming, although tired eyes was associated with the highest score. These results indicated that the physical problems related to the neck, shoulders, and backs were the most affected regions among the computer users, other ocular symptoms were the most frequently occurring health problems (Lanhers et al., 2016), and of the 59 included workers who use a computer for 3-6 h per day, the musculoskeletal problems were reported by $71.1 \%$ of subjects as compared to that for visual problems of $61.0 \%$ out (Talwar et al., 2009); thus, after physical discomfort, discomfort of the eye is the second most frequent problem reported by VDT operators. Tired eyes can be explained by the fact that high accommodation and convergence values are required for maintaining a clear vision at small distances from VDTs, and these values need to be maintained for the entire gaming duration. This invariably results in ocular fatigue. On the other hand, physical factors associated with discomfort had lower scores than did tired eyes due to frequent changes in the body posture to relieve physical stress.

We also found changes in visual functions after continuous computer gaming for $4 \mathrm{~h}$ in the present study. NPC, a visual function used to achieve single vision during near-distance work, showed a significant increase after the gaming session and recovered to the baseline level the next day. Qu et al. (2005) found that NPC was significantly increased after short-term VDT use. However, Yeow and Taylor (1991) found that NPC decreased with an increase in age, with no significant difference between VDT and non-VDT users. Hamed, David, and Marzieh (2013) reported that the evaluation of NPC helped in the differentiation of symptomatic and 
239

240

241

242

243

244

245

246

247

248

249

250

251

252

253

254

255

256

257

258

259

260

261

262

263

264

265

266

267

268

269

270

271

272

273

274

275

276

277

asymptomatic subjects, and that the average NPC value for break point was $11.7 \mathrm{~cm}$. While NPC is a measurement of how close one can bring a fixation target to the nose while maintaining fusion, NPA is used to assess the amplitude of accommodation. Accommodation is connected with the function of vergence maintained by extracocular muscles. Because of the interaction that occur between accommodation and vergence, the accommodation and convergence disturbances observed after the gaming session in the present study can be attributed to intra- and extra ocular muscle fatigue resulting from the prolonged continuous computer gaming.

Accommodative and vergence facilities permit the ability to sustain clear and single binocular vision during near-distance work. A healthy individual's accommodative facility should be binocularly clear within $10.0 \pm 5 \mathrm{cpm}$ (Scheiman \& Wick, 2002). In the present study, the value showed a significant change from 12.68 to $15.54 \mathrm{cpm}$. The vergence facility for single binocular vision also showed a significant change from 15.02 to $17.70 \mathrm{cpm}$; the norm is $15 \mathrm{cpm}$ (Weissberg, 2004). These changes may be associated with symptoms such as ocular fatigue, eyestrain, and blurred vision, although NPC and NPA showed significant changes within normal values. Both accommodative and vergence facilities recovered by the next morning.

The results of the present study also showed that near phoria (dissociated phoria) increased from $3.73 \Delta$ exophoria to $5.75 \Delta$ exophoria with the development of symptoms after continuous computer gaming for $4 \mathrm{~h}$, and it subsequently recovered to $3.68 \Delta$ exophoria by the following morning. This result is consistent with those of other studies (Yekta et al., 1989; Tsubota \& Nakamori, 1993) showing an exophoric shift in phoria due to near-distance tasks, with no significant change in distance phoria over time. According to other studies related to changes of phoria, Pickwell, Jenkins, and Yekta (1987) reported that $30 \mathrm{~min}$ of reading in inadequate illumination or from an abnormally close distance resulted in an increase in phoria with the development of ocular symptoms. Also, Yekta et al. (1989) found that near-dissociated phoria increased from $4.70 \Delta$ exophoria to $5.20 \Delta$ exophoria after $30 \mathrm{~min}$ of reading and decreased to $4.87 \Delta$ exophoria after $30 \mathrm{~min}$ of relaxation, with no accompanying symptoms. Collectively, these findings including our results suggest that near phoria for binocular vision changes to exophoria under the effect of visual stress caused by factors such as inappropriate illumination, abnormal working distance, and prolonged working hours.

The mean blinking rate at rest reportedly varies from 12 to 19 blinks per minute (Karson et al., 1981). Tsubota and Nakamori (1993) observed 22 blinks per minute under relaxed conditions and seven blinks per minute during VDT work. Patel et al. (1991) reported 18.4 blinks per minute before a computer task and 3.6 blinks per minute during the computer task. We found that the number of blinks per minute significantly decreased from 16.24 before the gaming session to 8.27 after $1 \mathrm{~h}$ of gaming and 9.51 after $4 \mathrm{~h}$ of continuous gaming. However, we do not know whether the decreased blink rate induces ocular fatigue, or vice versa. However, the blink rate may be an effective index for assessing visual fatigue during VDT tasks. Intentional blinking during VDT tasks is required to minimize visual fatigue. Blinking exercises have been shown to improve the glandular function and reduce the frequency of incomplete blinks (Murakami et al., 
278 2014; Downie \& Craig, 2017). Therefore, we highly recommend blink training to increase the 279 blinking rate during prolonged computer use.

280 Pearson's correlation analysis showed that ocular fatigue and blurred vision were weakly 281 related to NPA, whereas itchiness was weakly related to NPC. These subjective symptoms may 282 be provoked by the accommodation and convergence disturbances induced during prolonged 283 computer gaming. Although these changes are usually temporary, visual fatigue caused by long-

284 285 term VDT use tends to accumulate over time as reported by Murata et al. (1996).

Our study has a limitation that the results have not been compared with those of a control group. However, Qu et al. (2005) compared VDT and non-VDT users and reported that even short duration (1 h) of use of VDT leads to reduction in NPA, receding of NPC, and increase in near lateral exophoria. It is evident that signs derived from computer operation involves near work. VDT exposure in our study has more accelerated conditions (highly stressful conditions) than in the study by Qu et al. Therefore, we are of the opinion that the findings of the current study pertaining to physical and visual discomfort and binocular functions following continuous computer gaming are significant even in the absence of a control group. This study is limited by the small sample size that included participants with healthy eyes without binocular vision problems so that compounding variables associated with physical and ocular fatigue in the daily life of the individual were minimized. A larger sample of participants with binocular disorders is necessary for extensive estimation of the effects of prolonged continuous computer gaming. Also, the appeared points of physiological effects and the recovery were not exactly examined in this study.

The time-points of physiological effects and recovery were not exactly examined in this study. Nevertheless, our findings offer valuable insights and provide direct evidence of significant changes in physical and ocular symptoms and visual function after a 4-h period of computer game. The time-points of physiological effects could be variable due to influencing factors such as individual and ergonomic factors. The decreased accommodative functions in the subjects after performing VDT task for $2 \mathrm{~h}$ were recovered at the end of the 1-h lunch break (Saito et al., 1994). Accommodative functions after resting for $0.5 \mathrm{~h}$ following $1.5 \mathrm{~h}$ VDT task showed a tendency to return to the previous normal value (Yoo et al., 1992). These previous studies suggest that the recovery time of symptoms and signs may be depended on the strength of VDT work.

\section{CONCLUSIONS}

In summary, the findings clearly indicate that changes in visual functions evoke ocular symptoms after prolonged continuous computer gaming, which also induces physical symptoms. Although these symptoms are usually temporary, the accumulation of fatigues could be potential risk factors for irreversible physical and visual disturbances associated with computer overuse. Users may need rest to alleviate fatigue due to computer use. Moreover, individuals should be advised regarding their working hours. Therefore, it seems reasonable that all individuals should be advised to take breaks and periodically gaze into the distance to minimize accommodation 
318 and vergence disturbances; longer rest periods will result in lesser physical and ocular fatigue.

319

320

\section{ACKNOWLEDGEMENTS}

321 Not applicable.

322

323

324

325

326

327

328

329

330

331

332

333

334

335

336

337

338

339

340

341

342

343

344

345

346

347

348

349

350

351

352

353

354

355

356

357

\section{REFERENCES}

Abraham LM, Kuriakose T, Sivanandam V, Venkatesan N, Thomas R, Muliyil J. 2005. Amplitude of accommodation and its relation to refractive errors. Indian J Ophthalmol 53(2):105-108 DOI: 10.4103/0301-4738.16173.

Ahn DH. 2017. Korean policy on treatment and rehabilitation for adolescents' internet addiction. In: 2007 International Symposium on the Counseling and Treatment of Youth Internet Addiction. Seoul, Korea: National Youth Commission, 49.

Akinbinu TR, Mashalla YJ. 2014. Impact of computer technology on health: computer vision syndrome (CVS). Med Pract Rev 5(3):20-30 DOI: 10.5897/MPR.2014.0121.

Ames SL, Wolffsohn JS, Mcbrien NA. 2005. The development of a symptom questionnaire for assessing virtual reality viewing using a head-mounted display. Optom Vis Sci 82(3):168-176 DOI: 10.1097/01.OPX.0000156307.95086.6.

Berqqvist U, Wolgast E, Nilsson B, Voss M. 1995. The influence of VDT work on musculoskeletal disorders. Ergonomics 38(4):754-762 DOI: 10.1080/00140139508925147.

Downie LE, Craig JP, 2017. Tear film evaluation and management in soft contact lens wear: a systematic approach. Clin Exp Optom 100(5):438-458 DOI: 10.1111/cxo.12597.

Fenga C, Di Pietro R, Fenga P, Di Nola C, Spinella R, Cacciola A, Germanò D, Aragona $P$. 2007. Astenopia e lavoro al VDT: nostra esperienza. G Ital Med Lav Ergon 29(Suppl 3):500 501.

Gall R, Wick B, Bedell H. 1998. Vergence facility: establishing clinical utility. Optom Vis Sci 75(10):731-742 DOI: 10.1097/00006324-199810000-00018.

González-Pérez M, Susi R, Antona B, Barrio A, González E. 2014. The computer-vision symptom scale (CVSS17): development and initial validation. Invest Ophthalmol Vis Sci 55(7):4504-4511 DOI:10.1167/iovs.13-13818.

Griffiths MD, Kussa DJ, King DL. 2012. Video game addiction: past, present and future. Curr Psychiatry Rev 8(4):308-318 DOI: 10.2174/157340012803520414.

Hamed MM, David AG, Marzieh E. 2013. The relationship between binocular vision symptoms and near point of convergence. Indian J Ophthalmol 61(7):325-328 DOI: 10.4103/0301-4738.97553.

Hayes JR, Sheedy JE, Stelmack JA, Heaney CA. 2007. Computer use, symptoms, and quality of life. Optom Vis Sci 84(8):738-744 DOI: 10.1097/OPX.0b013e31812f7546.

James C, James D, Nie V, Schumacher T, Guest M, Tessier J, Marley J, Bohatko-Naismith J, Snodgrass S. 2018. Musculoskeletal discomfort and use of computers in the university environment. Appl Ergon 69:128-135 DOI: 10.1016/j.apergo.2018.01.013.

Karson CN, Berman KF, Donnelly EF, Mendelson WB, Kleinman JE, Wyatt RJ. 1981.

Peer) reviewing PDF | (2018:10:31788:2:0:NEW 19 Mar 2019) 
Speaking, thinking and blinking. Psychiatry Res 5(3):243-246 DOI: 10.1016/01651781(81)90070-6.

Kim T, Kang MY, Yoo MS, Lee D, Hong YC. 2016. Computer use at work is associated with self-reported depressive and anxiety disorder. Ann Occup Environ Med 28:57 DOI: 10.1186/s40557-016-0146-8.

Klussmann A, Gebhardt H, Liebers F, Rieger MA. 2008. Musculoskeletal symptoms of the upper extremities and the neck: a cross-sectional study on prevalence and symptom-predicting factors at visual display terminal (VDT) workstations. BMC Musculoskelet Disord 9:96 DOI: 10.1186/1471-2474-9-96.

Lanhers C, Pereira B, Garde G, Maublant C, Dutheil F, Coudeyre E. 2016. Evaluation of 'IPreventive': a digital preventive tool for musculoskeletal disorders in computer workers-a pilot cluster randomised trial. BMJ Open 6:e011304 DOI: 10.1136/bmjopen-2016-011304.

Murakami D, Blackie CA, Korb DR. 2014. Blinking exercises can be used to decrease partial blinking and improve gland function and symptoms in patients with evaporative dry eye. Denver: American Academy of Optometry. Available at https://www.aaopt.org/detail/knowledge-base-article/ (accessed 9 December 2018).

Murata K, Araki S, Yokoyama K, Yamashita K, Okumatsu T, Sakou S. 1996. Accumulation of VDT work-related visual fatigue assessed by visual evoked potential, near point distance and critical flicker fusion. Ind Health 34(2):61-69 DOI: 10.2486/indhealth.34.61.Parihar JKS, Jain VK, Chaturvedi P, Kaushik J, Jain G, Parihar AK. 2016. Computer and visual display terminals (VDT) vision syndrome (CVDTS). Med J Armed Forces India 72(3):270276 DOI: 10.1016/j.mjafi.2016.03.016.

Patel S, Henderson R, Bradley L, Galloway B, Hunter L. 1991. Effect of visual display unit use on blink rate and tear stability. Optom Vis Sci 68(11):888-892 DOI: 10.1097/00006324199111000-00010.

Pickwell D, Jenkins T, Yekta AA. 1987. The effect on fixation disparity and associated heterophoria of reading at an abnormally close distance. Ophthalmic Physiol Opt 7(4):345347 DOI: 10.1111/j.1475-1313.1987.tb00758.x.

Qu XM, Chu RY, Wang L, Yao PJ, Liu JR. 2005. Effects of short-term VDT usage on visual functions. Zhonghua Yan Ke Za Zhi 41(11):986-989 DOI: 10.3760/j:issn:04124081.2005.11.007.

Rikkers W, Lawrence D, Hafekost J, Zubrick SR. 2016. Internet use and electronic gaming by children and adolescents with emotional and behavioural problems in Australia - results from the second child and adolescent survey of mental health and wellbeing. BMC Public Health 16:399 DOI: 10.1186/s12889-016-3058-1.

Rosenfield M. 2011. Computer vision syndrome: a review of ocular causes and potential treatments. Ophthalmic Physiol Opt 31(5):502-515 DOI: 10.1111/j.1475-1313.2011.00834.x.

Saito S, Sotoyama M, Saito S, Taptagaporn S. 1994. Physiological indices of visual fatigue due to VDT operation: pupillary reflexes and accommodative responses. Ind Health 32(2):5766. 
398

399

400

401

402

403

404

405

406

407

408

409

410

411

412

413

414

415

416

417

418

419

420

421

422

423

424

425

426

427

428

429

430

431

432

433

434

435

436

437

Saquib N, Saquib J, Wahid A, Ahmed AA, Dhuhayr HE, Zaghloul MS, Ewid M, AlMazrou A. 2017. Video game addiction and psychological distress among expatriate adolescents in Saudi Arabia. Addict Behav Rep 6:112-217 DOI: 10.1016/j.abrep.2017.09.003.

Scheiman M, Gallaway M, Frantz KA, Peters RJ, Hatch S, Cuff M, Mitchell GL. 2003. Nearpoint of convergence: test procedure, target selection, and normative data. Optom Vis Sci 80(3):214-225 DOI: 10.1097/00006324-200303000-00011.

Scheiman M, Wick B. 2002. Clinical Management of Binocular Vision. Philadelphia: Lippincott Williams and Wilkins, 8-20.

Sung W. 2014. A study on the effect of the policy of online game shutdown on the game time of youth. Social Science Research Review 30(2):233-256.

Talwar R, Kapoor R, Puri K, Bansal K, Singh S. 2009. A study of visual and musculoskeletal health disorders among computer professionals in NCR Delhi. Indian J Community Med 34(4):326-328 DOI: 10.4103/0970-0218.58392.

The Korea Creative Content Agency. 2017. Game users survey report 2017. Available at http://www.kocca.kr/cop/bbs/view/B0000147/1833674.do? (accessed 25 June 2018 ).

Toomingas A. 2014. A definition of visual ergonomics. Appl Ergon 45(4):1263-1264 DOI: 10.1016/j.apergo.2014.03.004.

Tosha C, Borsting E, Ridder WH, Chase C. 2009. Accommodation response and visual discomfort. Ophthalmic Physiol Opt 29(6):625-633 DOI: 10.1111/j.1475-1313.2009.00687.x.

Tsubota K, Nakamori K. 1993. Dry eyes and video display terminals. $N$ Engl J Med 328(8):584 DOI: 10.1056/NEJM199302253280817.

Tyrrell RA, Leibowitz HW. 1990. The relation of vergence effort to reports of visual fatigue following prolonged near work. Hum Factors 32(3):341-357 DOI: 10.1177/001872089003200307.

Weissberg EM. 2004. Diagnostic techniques. In: Weissberg EW, eds. Essential of clinical binocular vision. St.Louis: Butterworth-Heinemann, 158-164.

Wittek CT, Finserås TR, Pallesen S, Mentzoni RA, Hanss D, Griffiths MD, Molde H. 2016. Prevalence and predictors of video game addiction: a study based on a national representative sample of gamers. Int J Ment Health Addict 14(5):672-686 DOI: 10.1007/s11469-015-9592-8.

World Health Organization(WHO). 1987. Visual display terminals and workers' health. Geneva: World Health Organization 80-81.

Wong EP, Fricke TR, Dinardo C. 2002. Interexaminer repeatability of a new, modified prentice card compared with established phoria tests. Optom Vis Sci 79(6):370-375 DOI: 10.1097/00006324-200206000-00010.

Yang SJ, Stewart R, Lee JY, Kim JM, Kim SW, Shin IS, Yoon JS. 2014. Prevalence and correlates of problematic internet experiences and computer-using time: a two-year longitudinal study in Korean school children. Psychiatry Investig 11(1):24-31 DOI: 10.4306/pi.2014.11.1.24.

Yekta AA, Pickwell LD, Jenkins TC. 1989. Binocular vision without visual stress. Optom Vis Sci 66(12):815-817 DOI: 10.1097/00006324-198912000-00002.

Peer) reviewing PDF | (2018:10:31788:2:0:NEW 19 Mar 2019) 
438 Yeow PT, Taylor SP. 1990. The effects of long-term VDT usage on the nature and incidence of 439 asthenopic symptoms. Applied Ergonomics 21(4):285-293 DOI: 10.1016/0003-6870(90)90199-8.

440 Yeow PT, Taylor SP. 1991. Effects of long-term visual display terminal usage on visual

441 functions. Optom Vis Sci 68(12):930-941 DOI: 10.1097/00006324-199112000-00004.

442 Yoo JS, Yoon JW, Kim JD. 1992. Influence of VDT work on accommodative function. $J$

$443 \quad$ Korean Ophthalmol Soc 33(7):693-397.

444 Zastrow M. 2017. News feature: is video game addiction really an addiction? Proc Natl Acad

445 Sci U S A 114(17):4268-4272 DOI: 10.1073/pnas.1705077114.

446 


\section{Table $\mathbf{1}$ (on next page)}

Changes in physical and ocular symptom scores after continuous computer gaming for $4 \mathrm{~h}$. 


\begin{tabular}{|c|c|c|c|}
\hline \multirow{2}{*}{ Symptoms } & \multicolumn{2}{|c|}{ Score, mean \pm SD } & \multirow{2}{*}{ Significance ${ }^{*}$} \\
\hline & Before gaming & After gaming & \\
\hline Physical discomfort & $0.39 \pm 0.78$ & $1.61 \pm 1.24$ & $\mathrm{t}=15.7, \mathrm{p}<0.001$ \\
\hline Shoulder & $0.48 \pm 0.81$ & $1.88 \pm 1.19$ & $\mathrm{t}=8.80, \mathrm{p}<0.001$ \\
\hline Neck & $0.44 \pm 0.81$ & $1.92 \pm 1.21$ & $\mathrm{t}=9.78, \mathrm{p}<0.001$ \\
\hline Back & $0.20 \pm 0.53$ & $1.16 \pm 1.15$ & $\mathrm{t}=6.60, \mathrm{p}<0.001$ \\
\hline Headache & $0.42 \pm 0.91$ & $1.46 \pm 1.30$ & $\mathrm{t}=6.76, \mathrm{p}<0.001$ \\
\hline Ocular discomfort & $0.50 \pm 0.83$ & $1.40 \pm 1.22$ & $\mathrm{t}=17.44, \mathrm{p}<0.001$ \\
\hline Red eyes & $0.48 \pm 0.81$ & $1.38 \pm 1.09$ & $\mathrm{t}=7.18, \mathrm{p}<0.001$ \\
\hline Eyestrain & $0.44 \pm 0.79$ & $1.58 \pm 1.03$ & $\mathrm{t}=8.32, \mathrm{p}<0.001$ \\
\hline Itchy eyes & $0.44 \pm 0.79$ & $0.82 \pm 1.00$ & $\mathrm{t}=2.57, \mathrm{p}=0.013$ \\
\hline Tired eyes & $0.94 \pm 0.98$ & $2.30 \pm 1.09$ & $\mathrm{t}=8.73, \mathrm{p}<0.001$ \\
\hline Dry eyes & $0.64 \pm 1.01$ & $1.64 \pm 1.34$ & $\mathrm{t}=6.86, \mathrm{p}<0.001$ \\
\hline Teary eyes & $0.34 \pm 0.80$ & $0.88 \pm 1.14$ & $\mathrm{t}=3.62, \mathrm{p}<0.001$ \\
\hline Irritated eyes & $0.34 \pm 0.66$ & $0.96 \pm 1.12$ & $\mathrm{t}=3.73, \mathrm{p}<0.001$ \\
\hline Blurred vision & $0.46 \pm 0.73$ & $1.60 \pm 1.20$ & $\mathrm{t}=7.28, \mathrm{p}<0.001$ \\
\hline Aching eyes & $0.40 \pm 0.76$ & $1.40 \pm 1.29$ & $\mathrm{t}=6.29, \mathrm{p}<0.001$ \\
\hline
\end{tabular}

2 Symptoms were scored on a scale from 0 (none) to 4 (very severe).

3 SD: standard deviation

$4{ }^{*}$ The p-values were determined using paired t-tests. Differences between the means were statistically significant $(\mathrm{p}<0.05)$. 


\section{Table 2 (on next page)}

Changes in binocular function after continuous computer gaming for $4 \mathrm{~h}$. 


\begin{tabular}{|c|c|c|c|c|}
\hline $\begin{array}{l}\text { Binocular function } \\
\text { (Expected values) }\end{array}$ & $\begin{array}{l}\text { Before gaming } \\
\text { (a) }\end{array}$ & $\begin{array}{l}\text { After gaming } \\
\text { (b) }\end{array}$ & $\begin{array}{l}\text { Following morning } \\
\text { (c) }\end{array}$ & $\begin{array}{l}\text { Significance } \\
\text { (Post hoc) }^{\S}\end{array}$ \\
\hline $\begin{array}{l}\mathrm{NPC}(\mathrm{cm}) \\
(2.5 \pm 2.5)\end{array}$ & $7.23 \pm 1.64$ & $8.77 \pm 1.60$ & $7.36 \pm 1.29$ & $\begin{array}{c}\mathrm{F}=47.83, \mathrm{p}<0.001 \\
(\mathrm{~b}>\mathrm{a}, \mathrm{c})\end{array}$ \\
\hline $\begin{array}{l}\text { NPA (cm) } \\
\text { (NA) }\end{array}$ & $7.79 \pm 1.44$ & $9.11 \pm 1.93$ & $7.78 \pm 1.49$ & $\begin{array}{c}\mathrm{F}=42.50, \mathrm{p}<0.001 \\
(\mathrm{~b}>\mathrm{a}, \mathrm{c})\end{array}$ \\
\hline $\begin{array}{l}\text { Phoria at distance }(\Delta) \\
(1 \pm 1 \text { exophoria) }\end{array}$ & $-0.76 \pm 1.71$ & $-0.83 \pm 2.25$ & $-0.62 \pm 1.69$ & $\mathrm{~F}=\underset{(\mathrm{ns})}{1.67, \mathrm{p}}=0.193$ \\
\hline $\begin{array}{l}\text { Phoria at near }(\Delta) \\
(3 \pm 3 \text { exophoria) }\end{array}$ & $-3.73 \pm 3.93$ & $-5.75 \pm 4.85$ & $-3.68 \pm 4.86$ & $\begin{array}{c}\mathrm{F}=18.39, \mathrm{p}<0.001 \\
(\mathrm{~b}>\mathrm{a}, \mathrm{c})\end{array}$ \\
\hline $\begin{array}{l}\text { Accommodative facility (cpm) } \\
(10 \pm 5)\end{array}$ & $14.42 \pm 3.20$ & $12.68 \pm 3.98$ & $15.54 \pm 2.95$ & $\begin{array}{c}\mathrm{F}=30.08, \mathrm{p}<0.001 \\
(\mathrm{c}>\mathrm{a}>\mathrm{b})\end{array}$ \\
\hline $\begin{array}{l}\text { Vergence facility }(\mathrm{cpm}) \\
(15 \pm 3)\end{array}$ & $16.94 \pm 3.16$ & $15.02 \pm 3.67$ & $17.70 \pm 3.41$ & $\begin{array}{c}\mathrm{F}=38.97, \mathrm{p}<0.001 \\
(\mathrm{c}>\mathrm{a}>\mathrm{b})\end{array}$ \\
\hline $\begin{array}{l}\text { Blink rate (per minute) } \\
\text { (12 to } 19)\end{array}$ & $16.24 \pm 5.14$ & $(8.27 \pm 5.40)^{\dagger}$ & $(9.51 \pm 5.28)^{\ddagger}$ & $\begin{array}{c}\mathrm{F}=106.29, \mathrm{p}<0.001 \\
(\mathrm{a}>\mathrm{b}, \mathrm{c})\end{array}$ \\
\hline
\end{tabular}

2 Data are expressed as means \pm standard deviations.

3 NPC: near point of convergence, NPA: near point of accommodation, NA: not applicable due to the value determined by 4 age or refractive errors, $\Delta$ : prism diopter, cpm: cycles per minute, ns: non-significant. "Expected values from Scheiman et 5 al. (2002), Weissberg (2004), and Karson et al. (1981). "Blink rate after $1 \mathrm{~h}$, Bink rate after $4 \mathrm{~h},{ }^{\S}$ Bonferroni correction 6 for multiple comparisons.

7 The p-values were determined using repeated measures analysis of variance. Negative and positive values for phoria 8 represent exophoria and esophoria (horizontal), respectively. Missing data are 15 persons for phoria and 10 persons for 9 blink rate. 
Figure 1

Changes in phoria during a continuous 4-h computer gaming session.

The symbols and error bars represent mean and standard deviations, respectively. Negative values denote exophoria and positive values denote esophoria (horizontal).

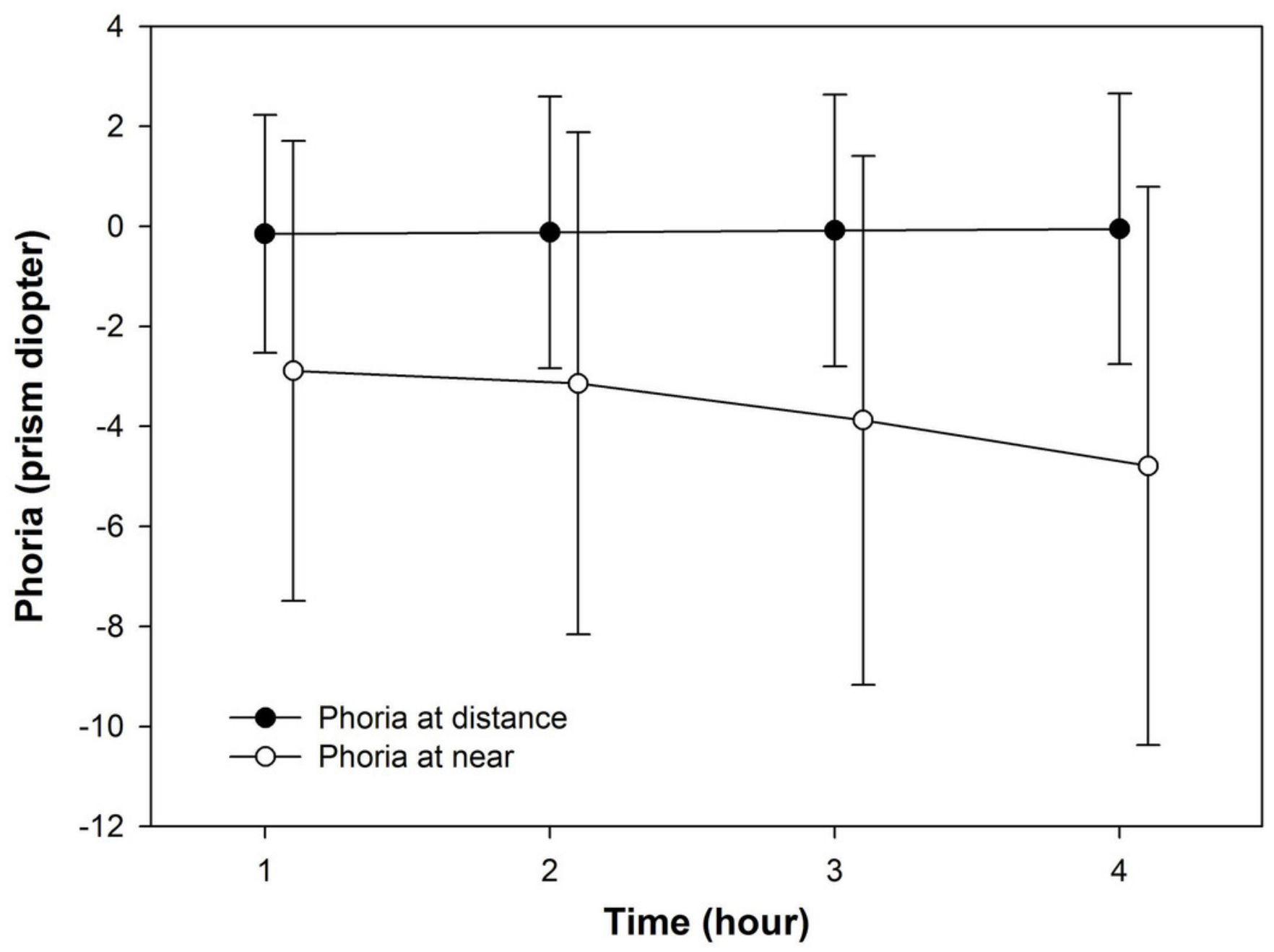

